\title{
Twisted ovarian cyst in women with uterine anomalies - a case report.
}

\author{
Prashant Gill, S.K. Jain, Shantanu vyas , Mahesh Mangal, K.M. Garg
}

(Key words: Bicornuateuterus ;mullerian agenesis; uterusdidelphys; Twisted ovarian cyst.)

\section{Introduction:}

Mullerian anomalies encompass a wide variety of malformations in the female genital tract. Their occurrence is sporadic and there is no evidence of familial inheritance (1). Of these anomalies, approximately $11 \%$ are uterus didelphys, which occurs when midline fusion of the mullerian ducts is arrested to a variable extent (2). They are associated with ovarian malposition and obstruction due to the presence of a transverse vaginal septum (3). There is a reported $20 \%$ incidence of renal anomalies in patients with uterus didelphys. We report a patient who was diagnosed as twisted right ovarian cyst and a bicornuate uterus.

\section{Case report:}

42 year old female presented with lump and pain in lower abdomen of 2 months duration. Pain was dullaching, continuous and non radiating. The severity of pain increased since last 4 days. The significant history was absence of menstrual cycle .she was married for 20 years and complained of dyspareunia.

Clinical examination revealed tenderness and guarding in lower abdomen. USG examination revealed a pelvic mass of $12 \mathrm{~cm} \times 13.5 \mathrm{~cm}$ of mixed echogenicity with cystic and solid areas suggestive of right ovarian cyst, further it was mentioned that uterus is not identifiable. Contrast enhanced CT scan reported a large thickwalled cyst $11 \times 10 \mathrm{~cm}$, arising from right adnexa, right ovary separatelycan not be visualized. Ulerus has two horns, with a fundal cleft of approximately $107 \mathrm{~cm}$; the intercornal angle is approximately $70^{\circ}$. Hence a diagnosis of twisted right ovarian cyst with bicornuate uterus was made and surgery planned.

At laprotomy, the right follopioan tube was stretched over the large twisted ovarian cyst. Uterus was bicornmate with larger right cornua. Hence right Salpingo-oophorectomy was performed. Postoperative recovery was uneventful and Specimen histopathological examination reported as features suggestive of twisted ovarian cyst .

\section{Discussion:}

The anomalies of the mullerian ducts has long been recognized. The various anomalies are the didelphic uterus, bicornuate uterus and septate uterus (Partial or Complete). Each has distinct anatomical characteristics and different clinical implications. Abnormalities of urinary tract can be found in conjunction with all three uterine malformations. Obstructive malformations almost always occur with renal agenesis on the obstructed side.

Genital malformations can be particularly disturbing to the patient and her family because they not only have reproductive implications but also significant psychological and sexual overtones that need to be addressed and dealt with in a sensitive and reassuring manner (4). Patients may present with cyclical abdominal pain, inability to conceive, dyspareunia, frequent loss of pregnancy and premature labour etc. The confusing clinical sign is the associated menstruation from the other side and the diagnosis may be missed if a careful examination is not performed in teenagers. Early accurate diagnosis and a thorough workup are essential for complete relief of symptoms and preservation of reproductive potential.

Correcting obstructed anomalies is important because hematometra and hematosalpinx may develop from retrograde menstruation (5). Uterine didelphys should be worked up with hysterosalpingogram, MRI, and intravenous pyelogram to diagnose the typically identified 2 separate uterine horns and cervices and to rule out urinary tract anomalies. Transvaginal ultrasonography and sonography can also be used (6).

Surgical management of uterine didelphys with obstructed hemivagina includes full excision and marsupialization of the vaginal septum, leaving enough pedicle to decrease possible bleeding in case the vaginal mucosa retracts (7). Non-obstructed manifestations have fewindications for septal resection because it may be difficult and may result in cervical incompetence or stenosis (8). The decision to perform metroplasty should be individualized and may take into consideration dyspareunia, recurrent abortions, or preterm births.

Our patients had infertility, but accepted this without any medical advise and check up at a designated centre may be because of poverty and medical ignorance. It was a chance diagnosis of bicornuate uterus due to twisted ovarian cyst. 


\section{Conclusion:}

Mullerian anomalies encompass a wide variety of genital abnormalities that often presents important diagnostic and therapentic problem (1). The Mayer Rokitansky - Kuster Hauser syndrome is an eponym often applied to individuals with mullerian duct anomalies in association with a solitary kidney. We present a chance diagnosis of bicornuate uterus with ipsilateral twisted right ovarian cyst.

\section{References:}

[1] Edmonds DK, Rokitansky syndrome and other Mullerian anomalies In: Balen AH, Creighton SM, Davies MC, editors. Paediatric and adolescent gynaecology. Cambridge, England: Cambridge University Press; 2004. Pp. 267-74

[2] Nahum GG. Uterine anomalies. How common are they, and what is their distribution among types? J Reprod Med. 1998;43-877-87. (PubMed.)

[3] Dabirashrafi H, Mohammad K, Moghadami-Tabrizi N. Ovarian malposition in women with uterine anomalies. Obstet Gynecol. 1997;83(2)293-94. (PubMed.).

[4] Spence JE. Vaginal and uterine anomalies in the paediatric and adolescent patient. J PediatrAdolescGynaecol 1998;11:3-11.

[5] Olive DL, Henderson DY. Endometriosis and mullerian anomalies. Obstet Gynecol. 1987;69(3 pt 1):412-15 (PubMed).

[6] Imaoka I, Wada A, Matsuo M, et al. MR imaging of disorders associated with female infertility: use in diagnosis, treatment, and management. Radiographics. 2003;23(6):1401-21. (PubMed.)

[7] Rock JA, Schlaff WD. Th obstetric consequences of uterovaginal anomalies. FertilSteril. 1985;43(5):681-92. (PubMed.)

[8] Rock JA. Surgery for anomalies of the mullerian ducts. In: Tompson JD, Rock JA, editors. Telind's Operative Gynaecology. $9^{\text {th }}$ ed. Philadelphia, Pa: JB Lippincott Williams and Wilkins; 2003. P 705. 